\title{
Motivated learning with digital learning tasks: what about autonomy and structure?
}

Citation for published version (APA):

Van Loon, A-M., Ros, A., \& Martens, R. (2012). Motivated learning with digital learning tasks: what about autonomy and structure? Educational Technology Research and Development, 60(6), 1015-1032.

https://doi.org/10.1007/s11423-012-9267-0

DOI:

10.1007/s11423-012-9267-0

Document status and date:

Published: 28/08/2012

Document Version:

Peer reviewed version

Document license:

CC BY-NC-ND

Please check the document version of this publication:

- A submitted manuscript is the version of the article upon submission and before peer-review. There can be important differences between the submitted version and the official published version of record. People interested in the research are advised to contact the author for the final version of the publication, or visit the DOI to the publisher's website.

- The final author version and the galley proof are versions of the publication after peer review.

- The final published version features the final layout of the paper including the volume, issue and page numbers.

Link to publication

\section{General rights}

Copyright and moral rights for the publications made accessible in the public portal are retained by the authors and/or other copyright owners and it is a condition of accessing publications that users recognise and abide by the legal requirements associated with these rights.

- Users may download and print one copy of any publication from the public portal for the purpose of private study or research.

- You may not further distribute the material or use it for any profit-making activity or commercial gain

- You may freely distribute the URL identifying the publication in the public portal.

If the publication is distributed under the terms of Article 25fa of the Dutch Copyright Act, indicated by the "Taverne" license above, please follow below link for the End User Agreement:

https://www.ou.nl/taverne-agreement

Take down policy

If you believe that this document breaches copyright please contact us at:

pure-support@ou.nl

providing details and we will investigate your claim.

Downloaded from https://research.ou.nl/ on date: 26 Apr. 2023 


\section{Motivated learning with digital learning tasks: what about autonomy and structure?}

\section{Anne-Marieke van Loon, Anje Ros \& Rob Martens}

Educational Technology Research and Development

A bi-monthly publication of the Association for Educational Communications \& Technology

ISSN 1042-1629

Education Tech Research Dev DOI 10.1007/s11423-012-9267-0

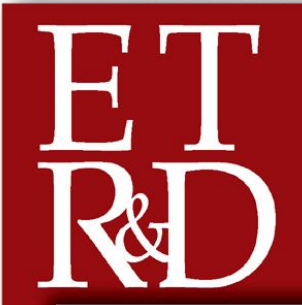

Educational Technology Research \& Development

Volume 54 • Number 1 • February 2006 ISSN 1042-1629

ONLINE FIRST

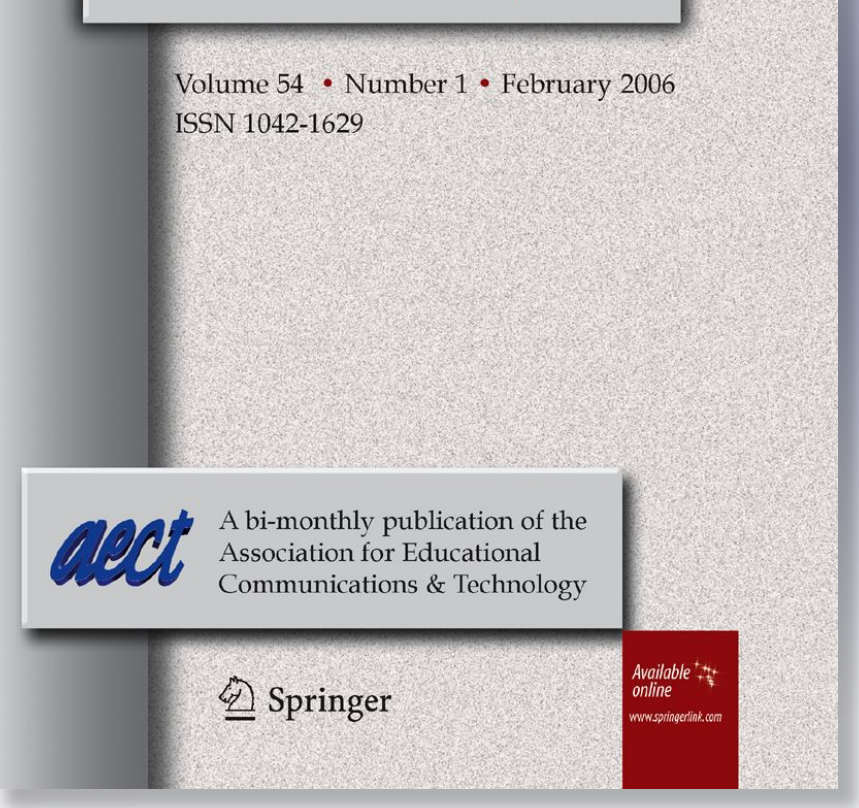


Your article is protected by copyright and all rights are held exclusively by Association for Educational Communications and Technology. This e-offprint is for personal use only and shall not be self-archived in electronic repositories. If you wish to self-archive your work, please use the accepted author's version for posting to your own website or your institution's repository. You may further deposit the accepted author's version on a funder's repository at a funder's request, provided it is not made publicly available until 12 months after publication. 


\title{
Motivated learning with digital learning tasks: what about autonomy and structure?
}

\author{
Anne-Marieke van Loon $\cdot$ Anje Ros $\cdot$ Rob Martens
}

(C) Association for Educational Communications and Technology 2012

\begin{abstract}
In the present study, the ways in which digital learning tasks contribute to students' intrinsic motivation and learning outcomes were examined. In particular, this study explored the relative contributions of autonomy support and the provision of structure in digital learning tasks. Participants were 320 fifth- and sixth-grade students from eight elementary schools throughout the Netherlands. The results show that a digital learning task that combined autonomy support and structure had a positive effect on both intrinsic motivation and learning outcomes in students. A digital learning task that only provided structure also had a positive effect on learning outcomes, but a digital learning task with only autonomy support did not yield a similar effect.
\end{abstract}

Keywords Digital learning task - Self-determination theory $\cdot$ Structure ·

Autonomy support $\cdot$ Intrinsic motivation

\section{Introduction}

When students are motivated, they tend to approach challenging tasks with greater eagerness, persevere in difficult situations, and take pleasure in their achievements (Stipek 1993). If students are motivated to learn, they often perform better (Ryan and Deci 2000a). Computer-supported learning environments offer features that may promote motivation (Liu et al. 2011; Mayer 2011). A digital problem-based learning (PBL) environment is an

A.-M. van Loon $(\bowtie)$

Open University of the Netherlands/KPC Groep, Kooikersweg 2, 5223 KA 's-Hertogenbosch, The Netherlands

e-mail: a.vanloon@kpcgroep.nl

A. Ros

Fontys Hogescholen/KPC Groep, Kooikersweg 2, $5223 \mathrm{KA}$ 's-Hertogenbosch, The Netherlands e-mail: a.ros@kpcgroep.nl

R. Martens

Open University of the Netherlands, Valkenburgerweg 167, 6419 AT Heerlen, The Netherlands e-mail: Rob.Martens@ou.nl 
example of a computer-supported learning environment that takes an instructional approach to motivate students (Liu and Bera 2005; Liu et al. 2011; Mayer 2011). In this type of environment, the emphasis is on solving complex problems in rich contexts to facilitate the development of higher-order thinking skills in students (Savery and Duffy 1995). Students have opportunities to apply their content knowledge and skills while working on contextualized problems (Dunlap 2005). Important aspects of PBL are that learning activities are student-centered, problems are the starting-point and stimulus for learning and new information is acquired through self-directed learning (Barrows 1996).

Making use of a hypermedia environment could enhance PBL, because hypermedia could provide richer information resources using different media (i.e. texts, images, and video sequences) in a more efficient way (Liu and Bera 2005; Narciss et al. 2007). The nonlinear, associative, and interactive capabilities of hypermedia can allow students to access information according to their own learning needs, and present multiple related problems in one environment (Hoffman and Richie 1997).

Certain researchers, however, have noted the increased demands on learners, as indicated by relatively high dropout rates and a diminished ability to focus during learning (Clark et al. 2010; Mayer 2011). Although PBL hypermedia environments provide rich and realistic contexts that allow learners to explore multiple options, the extensive amount of available information may cause them to become distracted from their learning objectives, lose their way in cyberspace, focus too much on irrelevant information, or absorb important information only cursorily (Salomon and Almog 1998).

A PBL hypermedia environment entails an increased degree of freedom that can discomfort students (Hoffman and Richie 1997). In these environments, students are often presented with a complex, ill-structured problem that they are expected to resolve and are able to choose whichever path they desire to solve the problem (Toprac 2011). Many learners do not make effective choices and may experience information overload (Azevedo and Witherspoon 2009; Liu and Bera 2005; Narciss and Körndle 1998). This reasoning is in line with the findings based on cognitive load theory (Sweller 2004), which posits that digital tasks imposing too much extraneous load hinder students from understanding the course content (Morrison and Anglin 2005).

An important question that emerges from this discussion is this: what should good digital learning environments contain to stimulate and motivate students to learn? This study is based on a digital PBL task in a hypermedia environment in which students' learning is initiated in the process of solving a complex problem. The challenge for teachers who design and use digital learning tasks in the classroom is to take advantage not only of the appealing appearance or novelty of the technology but also the didactic and educational substance of digital tasks that might improve motivation and promote learning.

This study builds upon the self-determination theory (SDT), which is an influential theory regarding motivation. By specifying the contextual environments that foster optimal learning, SDT is a relevant framework for the study of favorable conditions for digital PBL that enhance motivation and learning performance. First, we will look more closely at the design principles that can be derived from SDT.

\section{The self-determination theory and basic psychological needs}

SDT is a motivational theory that focuses on intrinsic motivation. The theory assumes that all individuals, regardless of background, have an intrinsic urge to explore, organize, understand, and assimilate with their environment (Deci et al. 1996). Because SDT 
assumes that everyone is naturally motivated, the theory's focus is on the conditions that facilitate or hinder intrinsic motivation (Ryan et al. 1997). Research reveals that to function optimally, an individual needs to satisfy three universal, innate, and essential psychological needs: the need for competence (White 1959), the need for autonomy (DeCharms 1968; Deci 1975), and the need for relatedness (Baumeister and Leary 1995). The need for competence is concerned with the experience of efficacy after completing a (learning) task (Ryan and Deci 2000a). The need for autonomy refers to the initiative and freedom that a person experiences when engaged in an activity in the absence of outside pressure with respect to his or her personal goals (Ryan and Deci 2000b). Finally, the need for relatedness concerns the feeling of connectedness to significant others, including teachers (Deci and Ryan 2000).

Students who are intrinsically motivated to learn often perform better in school (Ryan and Deci 2000a). Intrinsic motivation has been associated with high cognitive performance, indepth learning, and better recall of the acquired knowledge (Grolnick and Ryan 1987; Vansteenkiste et al. 2004). Intrinsically motivated students tend to be more curious (Kuhl 2000; Lewalter and Krapp 2004), exhibit greater exploratory behavior (Martens et al. 2004), and focus more on understanding rather than simply memorizing (Deci and Ryan 2008).

If a digital learning environment motivates and encourages learners to learn with greater depth, students should experience both autonomy and competence. Both of these needs may be fulfilled by the provision of autonomy support and structure in the digital learning environment.

\section{The roles of autonomy support and structure}

An environment with autonomy support is an environment in which external pressure is minimal, the personal goals of students are recognized (Deci and Ryan 2000, 2008), and choices are offered (Zuckerman et al. 1978). Being able to choose from among several options makes students feel more in control of their actions (Reeve et al. 2003). Research by Cordova and Lepper (1996) shows that when students work on a meaningful digital learning task that presents options, their intrinsic motivation levels are higher. Students are more engaged in the task, employ more deep-level learning, and learn more in a shorter amount of time. In addition to offering choices, providing a rationale for a task can also promote a sense of autonomy. If students receive a meaningful explanation of the purpose behind a certain learning task, they are likely to be more personally engaged in the learning task and, therefore, to be more motivated to learn (Deci et al. 1994). Autonomy-supportive language in learning tasks is characterized by non-directive language that encourages students to take the initiative (Deci et al. 1996). Research shows that environments that are autonomy-supportive help to fulfill the need for autonomy (Reeve et al. 2007) and foster greater intrinsic motivation in students (Reeve and Jang 2006). Such environments stimulate students' curiosity and encourage them to confront challenges (Flink et al. 1990; Ryan and Grolnick 1986).

There is a risk, however, that autonomy-supportive environments create too much associative distraction and overwhelm students with too many choices. Research by Martens et al. (2004) shows that students with high intrinsic motivation engage in greater exploratory behavior during digital learning tasks. Exploratory behavior, however, increases the likelihood of "getting lost" and following ineffective online learning paths. The risk is that, given the nonlinear and associative visual appeal of the digital task, the learner will wander from one item to another. As a consequence learners will only construct shallow associative cognitive networks which have no intellectual merit (Okan 2003; 
Salomon and Almog 1998). Thus, in addition to autonomy support, structure also plays a key role in an optimal digital learning environment (Guay et al. 2008).

Providing structure makes the learning environment less chaotic and more consistent and predictable for students. Moreover, from a motivational point of view, structure enables students to feel more competent (Grolnick and Ryan 1989; Skinner and Belmont 1993; Tucker et al. 2002). According to SDT, structure is of secondary importance compared with autonomy support in an optimal learning environment (Guay et al. 2008). Providing structure means providing clear goals and expectations for students and explicitly describing the consequences of achieving (or not achieving) those goals (Connell 1990). Providing structure also means providing help, support, appropriate strategies, and guidance for students to carry out a task successfully (Connell 1990; Skinner and Belmont 1993). Finally, structure requires providing students with clear procedures to follow (Reeve et al. 2004). Structure is associated not only with positive learning outcomes but also with greater learner engagement (Skinner and Belmont 1993; Tucker et al. 2002), lower passivity with regard to learning, and less school-avoidant behavior (Patrick et al. 2003).

Providing structure for students is not the opposite of providing autonomy support, however (Ryan 1993). According to Reeve et al. (2004), autonomy support and structure are separate dimensions of a teaching style that motivates students. In fact, the opposite of an autonomy-supportive environment is a controlling environment (Black and Deci 2000; Koestner et al. 1984). A controlling environment is characterized by extrinsic incentives and pressuring language that tend to interfere with student motivation (Reeve et al. 2004).

The combined influence of autonomy and structure on learning and motivation has not yet been empirically examined in the context of digital tasks but only in physical learning environments. Research studies on learning in the classroom show that offering choices and providing structure together produce positive effects on student motivation and the extent of self-regulated learning (Jang et al. 2010; Sierens et al. 2009). In an empirical study among 526 eleventh- to twelfth-grade students, Sierens et al. (2009) found that structure was associated with more self-regulated learning only under conditions of moderate and high autonomy support. Therefore, teachers who want their students to be more self-regulated in their learning should provide help, goals, and expectations in ways that support autonomy. Jang et al. (2010) studied the effect of autonomy support and structure in a sample of 133 teachers and 2,523 students. The authors concluded that the elements of structure (e.g. clear expectations and goals) had to be offered in an autonomysupportive way to enhance student engagement.

\section{The present study and hypotheses}

Research on the proper balance between autonomy support and structure is particularly relevant to PBL in a hypermedia environment. Digital PBL tasks in the classroom often offer a large amount of information without structure, thereby increasing the risk of information overload and superficial information processing (Narciss and Körndle 1998). The challenge is to create a digital learning task that provides students with choices and guidance. This study was based on the assumption that digital PBL tasks should provide both autonomy support and structure and that both dimensions positively influence students' intrinsic motivation and learning outcomes. Currently, however, there is a lack of scientific research on autonomy support and structure in a hypermedia learning environment. Particularly with the emergence of digital PBL tasks in education it is important to examine whether there is evidence to support this type of task design. 
This study aims to answer the following question: "In what ways can digital tasks based on PBL in a hypermedia environment contribute to the motivation and learning outcomes of students?" In summary, we examine the combined and relative influence of autonomy support and structure on learning in digital PBL hypermedia environments.

To answer the research question, this study explores three hypotheses. The first hypothesis (1A) is that in an autonomy-supportive digital learning task in which external pressure is minimal and choices are offered, students experience a greater sense of autonomy, and (1B) providing structure in a digital learning task makes the task predictable and offers enough guidance for students to experience a greater sense of competence.

Because the nature of the digital learning task also affects intrinsic motivation and learning outcomes, the second hypothesis (2) is that an autonomy-supportive digital learning task with structure contributes to a higher degree of intrinsic motivation.

The third hypothesis (3) is that an autonomy-supportive digital learning task with structure yields better learning outcomes.

\section{Methodology}

Design

In this research, we examined the effects of autonomy support and the provision of structure on motivation and learning outcomes in a digital learning environment. The research was experimental in nature and based on a 2 (with or without autonomy support) by 2 (with or without structure) design. Students from all the appropriate classrooms within a school were randomly selected and assigned to one of the four experimental conditions. Because students within a school were randomly selected and assigned to one of the four experimental conditions, the effect of the school as a factor on the motivation and learning outcomes of students was minimized. We designed a digital learning task that was used in each of the four experimental conditions. The conditions differed in their degrees of autonomy support and structure. Learning condition 1 involved a digital task with autonomy support and structure. Learning condition 2 involved a digital task with structure but without autonomy support. Learning condition 3 involved a digital task with autonomy support but without structure. Learning condition 4 involved a digital task with neither autonomy support nor structure. Table 1 presents the factorial design with sample sizes by learning condition.

\section{Participants}

The study took place in the Netherlands. Participants were 320 fifth- and sixth-grade students from eight elementary schools across the country. The mean age of the students at

Table 1 Factorial design with sample sizes by learning condition

\begin{tabular}{lll}
\hline Structure & Autonomy support & \\
\cline { 2 - 3 } & +Autonomy support & -Autonomy support \\
\hline +Structure & Learning condition 1 & $\begin{array}{l}\text { Learning condition 2 } \\
n=80\end{array}$ \\
-Structure & $n=80$ & $\begin{array}{l}\text { Learning condition 4 } \\
n=80\end{array}$ \\
& Learning condition 3 & \\
\hline
\end{tabular}


the outset of the study was 11.7 years $(S D=.63$, range $=10.0-13.6$ years $)$. A total of 160 boys and 160 girls from 12 different classrooms participated. On the basis of reports issued by the National Board of Education, we assumed that the learning outcomes of the students from the participating schools would be representative of the level achieved by their peers at other schools throughout the country. We selected the participating schools according to two criteria: (1) the students in these schools were accustomed to work independently, and (2) these schools integrated working with computers into the curriculum.

The task was incorporated into the regular curriculum in the classroom. Students received no reward or extra credit for their participation.

In every participating class, students were randomly assigned to one of four conditions. In total, we randomly assigned 80 students (38 boys, 42 girls) to condition 1 with autonomy support and structure, 80 students (41 boys, 39 girls), to condition 2 with structure but without autonomy support, 80 students (46 boys, 34 girls) to condition 3 with autonomy support but without structure, and 80 students ( 35 boys, 45 girls) to condition 4 with neither autonomy support nor structure (Table 1). No student dropped out of the experiment.

\section{Digital learning task, design features and cognitive tools}

The digital PBL task in this study incorporates design features that are supported by PBL and hypermedia learning.

PBL is an instructional approach that exemplifies authentic learning and emphasizes solving problems in rich contexts (Dunlap 2005). Compared with the main characteristics of PBL (Barrows 1996) the digital PBL task in this study was a structured PBL-like activity. It contained most aspects of PBL, namely:

- Learning is student-centered as students assume a major responsibility for their own learning; in the task in this study students themselves had to solve a problem about advertising with their own arguments and findings.

- Teachers are facilitators or guides; in this task there was electronic guidance. For example students could use a roadmap to understand and manage the problem better.

- Problems form the organizing focus and stimulus for learning; in this task students had to solve a problem about the need to convey a clear message in advertising.

- Problems, similar to those one would face in future professions, are a vehicle for the development of problem-solving skills; students were asked to play the role of an advertising creator who had to encourage people to buy a product.

- New information is acquired through self-directed learning; students had access to cognitive tools that facilitated the learning process. For example, students could use an information database to learn from their own study and research and acquire new information.

The task in this study was more of a structured PBL-like activity because one tenet of PBL, that learning does occur in small groups, was not met. In this study students learned individually.

The task consisted of a hypermedia electronic learning environment where students could navigate freely. The task was composed of hypertext with images, graphics and video. The content of the task related to the need to convey a clear message in advertising. In all conditions, the introduction of the task began by presenting a problem situation that was situated in a rich context with different hypermedia formats (i.e. text, graphics, video) so that students could see the complexity of the problem from multiple perspectives. 
Specifically, students were asked to play the role of an advertising creator who had to insure good advertising to encourage people to buy a product. All the students read instructions for the task so that they knew what was expected of them. The instructions were as follows: "In this task, you are a creator of advertisements. You are going to decide what good advertising is and identify the tricks used in advertisements to ensure that customers really do buy more." Also, the task provided a digital information database with advertisements and online sources with hyperlinks so students could navigate freely on the internet to facilitate knowledge acquisition and to solve the problem. In addition in all conditions they had access to computer-based cognitive tools that facilitated the learning process (Lajoie 1993).

Cognitive tools are computer-based instruments that assist learners in accomplishing complex cognitive tasks. (Lajoie 1993). Lajoie categorizes cognitive tools as follows: (1) tools that share the cognitive load, (2) tools that support cognitive processes, (3) tools that support cognitive activities that would be out of reach otherwise, and (4) tools that allow hypothesis generation and testing. Tools in this study could be grouped into categories 1 and 2. Tools that share cognitive overload existed of the problem presentation students received, and an information database with online sources and examples of advertisements so students could navigate to acquire information about advertising and to solve the problem. Tools supporting cognitive processes were a digital roadmap of the stages required to complete the task successfully and a template to interpret and organize information and present methods for solving the problem (a Word or PowerPoint document). See Fig. 1 for a visual presentation of the start screen of the task.

The assignment and the basic features of the task (as described above) were the same for each student in all conditions. The only differences between the conditions were associated with autonomy support and structure.

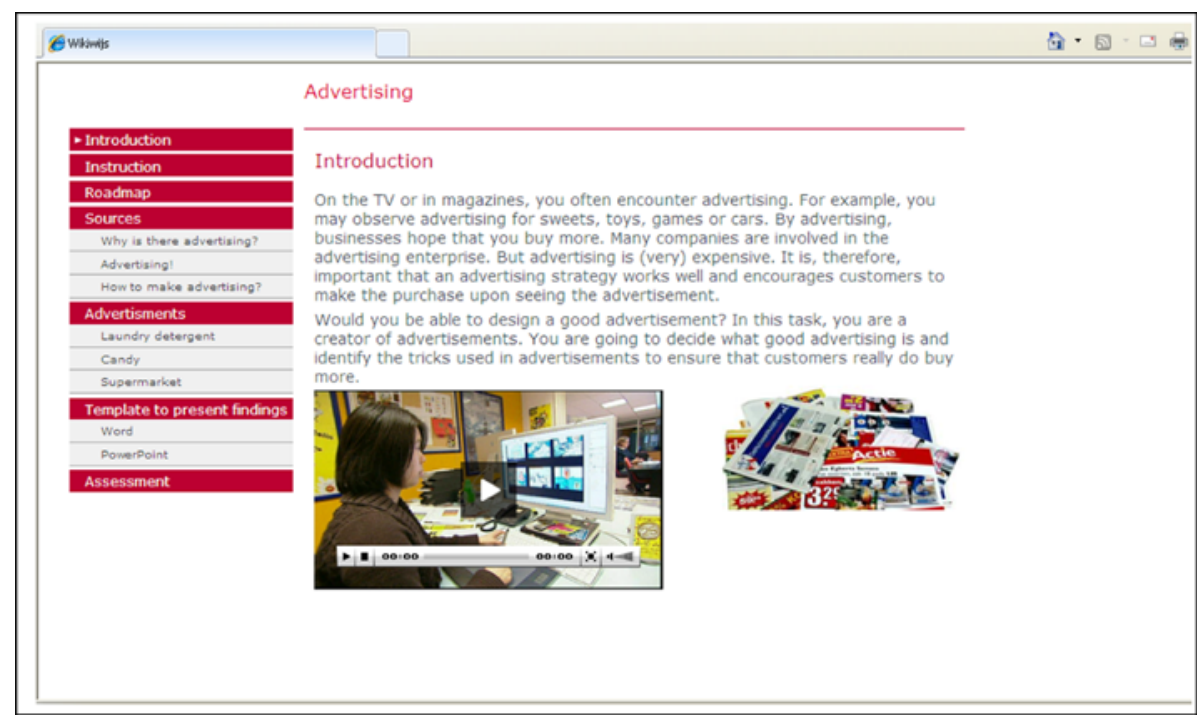

Fig. 1 Visual presentation of the start screen of the task in condition 1 
The digital learning task in condition 1 (with autonomy support and structure) provided options and structural guidance (Fig. 1). In terms of autonomy support, students had control over the content (i.e. the student could select an advertisement for him/herself), online sources (i.e. the student could search for information on websites of their own choice), and computer program (i.e. the student could choose to complete the task in Word or PowerPoint). An explanation was given about the relevance of the task to their learning. The autonomy-supportive task was also characterized by language that was non-directive and encouraged initiative (i.e. "You can make use of ...," and "You can do this task."). In terms of structure, students were given information to support their achievement of the learning goals, such as a roadmap of the stages required to complete the task successfully. Additionally, there was clarity regarding the way in which the finished product would be assessed. Lastly, the task with structure also provided clear procedures so that the students knew how long they were allowed to work on the task and what they could do when they had finished their work.

The digital learning task in condition 2 (without autonomy support but with structure) offered no choices and only structural guidance. Students were instructed to use a particular advertisement, to use only a set of recommended online sources, and to complete the task in either Word or PowerPoint. The relevance of the task was not explained. The language was directive (i.e. "You should do this task," and "You are expected to perform the task properly."). In terms of structure, information was given to support students' achievement of the learning goals, such as a roadmap of the stages required to complete the task successfully. Clear procedures and information regarding the way in which the finished product would be assessed were available.

The digital learning task in condition 3 (with autonomy support but without structure) offered choices and no structural guidance. Students were allowed to choose their own content, online sources, and program to present their findings. An explanation was given about the relevance of the task. The autonomy-supportive task was characterized by language that was non-directive and encouraged initiative. In terms of structure, no information was given to insure achievement of the learning goals; students were not given a roadmap of the stages required to complete the task successfully. Students were not told how the finished product would be assessed, nor did they receive a description of the procedures. Thus, they did not know how long they were allowed to work on the task and what they could do when they had finished their work.

The digital learning task in condition 4 (without structure and without autonomy support) offered no choices and no structural guidance. Students were required to use a particular advertisement, to use the recommended online sources, and to complete the task either in Word or PowerPoint. There was no explanation of the relevance of the task. The language was directive. In terms of structure, no information (e.g. a roadmap) was provided to support students' achievement of the learning goals. Students were not given a description of the procedures nor were they told how the finished product would be assessed.

\section{Procedure}

The intervention was conducted in separate rooms at the different schools. A number of the schools had special computer rooms available for the task, which meant that all the students were able to work on the task at the same time. In other schools, the students had 
to work during different sessions. The intervention was conducted during a single session and took approximately $1.5 \mathrm{~h}$ for each learner. An experimenter explained the task at the beginning of the session. The teacher was present but played no active role. The students completed the task independently and were not allowed to work together. Students were allowed to ask questions but were only given minimal help. Teachers were not allowed to give instructions. At the end of the task, each student filled out a questionnaire concerning the extent to which he or she had been motivated to complete the task and the degree of autonomy and competence that he or she had experienced.

Measures

\section{Perceived autonomy, perceived competence, and intrinsic motivation}

To measure the intrinsic motivation of students, we used the Intrinsic Motivation Inventory (IMI), which was originally developed by Ryan (1982). The IMI is a structured written questionnaire proven by McAuley et al. (1987) to be reliable and valid. The subscale "interest/enjoyment" from the IMI contains seven items that measure intrinsic motivation (e.g. "I enjoyed doing this activity very much" and "This activity was fun to do."). The perceived degrees of competence and autonomy were measured by questions based on the IMI subscales of "perceived competence" that consisted of six items (e.g. "I am satisfied with my performance in this task" and "I was pretty skilled at this task") and "perceived freedom of choice" that consisted of seven items (e.g. "I believe I had some choice about doing this activity" and "I felt like it was not my own choice to do this task," which was reverse coded). Each item is presented in the form of a statement about which the respondent indicates his or her degree of agreement or disagreement on a seven-point Likert scale (with a score of one indicating "totally disagree" and a score of seven indicating "totally agree"). In this sample, the reliability was high for all three scales: intrinsic motivation $(\alpha=.95)$, perceived autonomy $(\alpha=.95)$, and perceived competence $(\alpha=.93)$. No significant correlation was observed between perceived autonomy and perceived competence, which suggested that these variables were independent. To detect the possible issue of multicollinearity of perceived autonomy and perceived competence, we examined the impact on the precision of estimation of the regressors, with the result being reflected in the variance inflation index (VIF). If the largest VIF is greater than 10, there is cause for concern (Bowerman and O'Connell 1990). In this study, none of the VIF values was greater than 10 (maximum $\mathrm{VIF}=1.00$ ). A tolerance below .2 also indicates a potential problem (Menard 1995), but this result was not found in our data (minimum tolerance $=.99$ ). Thus, multicollinearity was not detected, making it possible to interpret the effects of perceived autonomy and perceived competence in a reliable manner.

\section{Learning outcomes}

The learning outcomes were measured by assessing the learning presentations (Word or PowerPoint document) created by the students. The students had to take the role of an advertising creator and produce a Word or PowerPoint document about effective advertising based on their research on the Internet. The quality of the learning products was assessed by a standard scoring form based on the learning goals of the task. The scoring form consisted of four areas in which students could earn points: the number of techniques that advertisers use to make customers buy more (maximum three points), the strengths of the advertisement (maximum two points), suggestions for how to improve the advertising 
message (maximum two points), and the readability of the report (maximum one point). Students could earn a maximum of eight points. Two independent reviewers scored all of the products. There was a high inter-rater reliability between the ratings of the two reviewers $(r=.95, p<.001)$.

\section{Results}

Effects of digital learning conditions with autonomy support on perceived autonomy (hypothesis 1A)

First, we explored the effect of the digital learning conditions with autonomy support on perceived autonomy. A general linear model univariate analysis of variance indicated that the main effect of autonomy support on perceived autonomy was significant $(F(1$, $316)=610.27, p<.001$, partial $\left.\eta^{2}=.66\right)$. There was no significant interaction between the provision of structure and autonomy support on perceived autonomy $(F(1,316)=.86$, $p=.356$, partial $\left.\eta^{2}=.00\right)$. The perceived autonomy scores in the conditions with autonomy support ( 1 and 3$)(M=5.79, S D=1.07)$ were higher than the scores in the conditions without autonomy support (2 and 4) $(M=2.71, S D=1.16)$. Thus, students experienced a greater sense of autonomy in the autonomy-supportive conditions.

Effects of digital learning conditions with structure on perceived competence (hypothesis 1B)

Second, we explored the impact of the digital learning conditions with structure on perceived competence. A general linear model univariate analysis of variance showed that the main effect of structure on perceived competence was significant $(F(1,316)=217.65$, $p<.001$, partial $\eta^{2}=.41$ ). There was no significant interaction between the provision of structure and autonomy support on perceived competence $(F(1,316)=2.49, p=.116$, partial $\left.\eta^{2}=.01\right)$. Students under conditions with structure $(1$ and 2$)(M=5.55$, $S D=1.10)$ scored higher on perceived competence than students under conditions without structure (3 and 4$)(M=3.65, S D=1.21)$. Thus, providing structure in the learning environment resulted in a greater sense of competence.

Effects of digital learning conditions on intrinsic motivation (hypothesis 2)

We analyzed the relationship between digital learning conditions and intrinsic motivation. A general linear model univariate analysis of variance was conducted with intrinsic motivation as the dependent variable and autonomy support (with or without) and provision of structure (with or without) as the independent variables. The main effect of autonomy support on intrinsic motivation was significant $(F(1,316)=69.86, p<.001$, partial $\left.\eta^{2}=.18\right)$. The main effect of structure on intrinsic motivation was also significant $\left(F(1,316)=70.29, p<.001\right.$, partial $\left.\eta^{2}=.18\right)$, as was the interaction between autonomy support and structure $\left(F(1,316)=14.60, p<.001\right.$, partial $\left.\eta^{2}=.04\right)$. These results meant that the effect of structure on intrinsic motivation was different in conditions with autonomy support from that in conditions without autonomy support. Simple effects analysis showed significant differences in the mean intrinsic motivation between providing structure together with autonomy support $(p<.005)$ and providing structure in the absence 
of autonomy support $(p<.001)$. As shown in Table 2 , the intrinsic motivation of students was highest in the condition with both autonomy support and structure (condition 1) $(M=5.83, S D=1.11)$, and lowest in the condition with neither autonomy support nor structure (condition 4) $(M=3.51, S D=1.42)$. These findings showed that the existence of an autonomy-supportive condition with structure had a positive influence on intrinsic motivation. When both autonomy support and structure were absent, low intrinsic motivation was evident.

Effects of digital learning conditions on learning outcomes (hypothesis 3)

Next, we analyzed the effects of the digital learning conditions on learning outcomes. A general linear model univariate analysis of variance was conducted with learning outcomes as the dependent variable and autonomy support (with or without) and structure (with or without) as the independent variables. The main effect of structure on learning outcomes was significant $\left(F(1,316)=191.06, p<.001\right.$, partial $\left.\eta^{2}=.38\right)$. The main effect of autonomy support on learning outcomes was not significant $(F(1,316)=1.25, p=.264$, partial $\left.\eta^{2}=.00\right)$. The interaction between autonomy support and structure on learning outcomes was significant $\left(F(1,316)=16.05, p<.001\right.$, partial $\left.\eta^{2}=.05\right)$, which meant that the effect of structure on learning outcomes was different in conditions with autonomy support from that in conditions without autonomy support. Simple effects analysis showed significant differences in the mean learning outcome between providing structure when there was autonomy support $(p<.001)$ and providing structure in the absence of autonomy support $(p<.001)$. Table 2 shows that the condition with both autonomy support and structure (condition 1) produced the best learning outcomes $(M=5.59, S D=1.35)$. Students scored slightly lower when they were provided with structure but no autonomy support (condition 2) $(M=4.70, S D=1.52$.). In the condition with neither autonomy support nor structure (condition 4$)$, even lower scores were found $(M=3.00, S D=1.66)$. The lowest learning outcomes were achieved in the condition in which autonomy support was given without structure (condition 3) $(M=2.50, S D=1.64)$.

Perceived autonomy and perceived competence increase intrinsic motivation and learning outcomes

The relative effects of perceived autonomy and perceived competence on intrinsic motivation and learning outcomes were examined by hierarchical regression analyses using the enter method. The results are displayed in Table 3 , which shows that perceived competence was the strongest predictor of learning outcomes $(\beta=.48)$ and intrinsic motivation $(\beta=.50)$. In addition, perceived autonomy had a significant effect on intrinsic motivation $(\beta=.44)$ but not on learning outcomes $(\beta=.02)$.

Table 2 Mean scores (and standard deviations) for all measures as a function of digital learning condition

\begin{tabular}{lllll}
\hline & $\begin{array}{l}\text { Learning } \\
\text { condition 1 }\end{array}$ & $\begin{array}{l}\text { Learning } \\
\text { condition 2 }\end{array}$ & $\begin{array}{l}\text { Learning } \\
\text { condition 3 }\end{array}$ & $\begin{array}{l}\text { Learning } \\
\text { condition 4 }\end{array}$ \\
\hline Perceived autonomy & $5.78(1.10)$ & $2.82(1.25)$ & $5.79(1.04)$ & $2.60(1.05)$ \\
Perceived competence & $5.50(1.14)$ & $5.59(1.06)$ & $3.81(1.19)$ & $3.49(1.21)$ \\
Intrinsic motivation & $5.83(1.11)$ & $5.20(1.26)$ & $5.20(1.14)$ & $3.51(1.42)$ \\
Learning outcomes & $5.59(1.35)$ & $4.70(1.52)$ & $2.50(1.64)$ & $3.00(1.66)$ \\
\hline
\end{tabular}


Table 3 Results of hierarchical regression analyses predicting intrinsic motivation and learning outcomes by perceived competence and perceived autonomy

\begin{tabular}{|c|c|c|c|c|c|c|}
\hline & \multicolumn{3}{|c|}{ Intrinsic motivation } & \multicolumn{3}{|c|}{ Learning outcomes } \\
\hline & $\beta$ & $S E B$ & $t$ & $\beta$ & $S E B$ & $t$ \\
\hline \multicolumn{7}{|l|}{ Step 1} \\
\hline Perceived competence & $.54 * * *$ & .05 & 11.40 & $.48 * * *$ & .07 & 9.74 \\
\hline$\Delta R^{2}$ & $.29 * * *$ & & & $.23 * * *$ & & \\
\hline \multicolumn{7}{|l|}{ Step 2} \\
\hline Perceived competence & $.50 * * *$ & .04 & 12.38 & $.48 * * *$ & .07 & 9.66 \\
\hline Perceived autonomy & $.44 * * *$ & .03 & 10.69 & .02 & .05 & .46 \\
\hline$\Delta R^{2}$ & $.19 * * *$ & & & .00 & & \\
\hline
\end{tabular}

In addition, the effect of intrinsic motivation on learning outcomes was examined by regression analyses using the enter method. Results show that intrinsic motivation was a good predictor of learning outcomes $(t(318)=5.80, p<.001, \beta=.31)$. Because intrinsic motivation significantly predicted learning outcomes and structure was significantly related to both enhanced intrinsic motivation and learning outcomes, an additional mediation analysis was performed that treated the relationship between structure and learning outcomes mediated by intrinsic motivation. This was done by the Sobel (1982) that assessed whether a mediation effect of intrinsic motivation is significant. This showed that the indirect path was significant and that intrinsic motivation was a significant mediator between structure and learning outcomes $(p<.05)$. There was partial mediation; intrinsic motivation accounts for some, but not all, of the relationship between structure and learning outcomes. The standardized regression coefficient between structure and learning outcomes $(\beta=.60, p<.001)$ decreased when we controlled for intrinsic motivation $(\beta=.55, p<.001)$.

\section{Discussion}

The aim of the study was to explore the ways in which digital learning tasks featuring PBL in a hypermedia environment contribute to the level of intrinsic motivation and learning outcomes in students. Although digital PBL tasks are used in classroom teaching with increasing frequency, there is a lack of research informing the optimization of structure and autonomy support in such tasks.

The first hypothesis was confirmed in its entirety. Specifically, students provided with autonomy support experienced a greater sense of autonomy, and students provided with structure experienced a greater sense of competence. Results suggest that perceived autonomy increases when a digital learning task supports autonomy by offering choices, a rationale for a task, and non-directive language. Further, an autonomy-supportive digital learning task helps to fulfill the need for autonomy because students can experience freedom in the activity (Reeve et al. 2007). A digital learning task that provides structure through clear expectations, guidance, and procedures contributes to greater perceived competence. This finding is consistent with previous findings that the provision of structure makes a learning task consistent and predictable and, in turn, helps students to feel more 
competent (Connell 1990; Grolnick and Ryan 1989; Skinner and Belmont 1993; Tucker et al. 2002).

The second hypothesis was that a digital learning task characterized by both autonomy support and structure would have a positive effect on intrinsic motivation. This hypothesis was also supported by the results, though the occurrence of both dimensions was not necessary for promoting intrinsic motivation. The results showed that even a single dimension (autonomy support or structure) was sufficient to foster intrinsic motivation. The positive interaction suggests, however, that when both autonomy support and structure are present they are mutually supportive and result in high motivation. If both are absent, however, low intrinsic motivation results. This finding concurs with previous research suggesting that environments that inhibit the fulfillment of these needs yield fewer optimal forms of motivation (Deci and Ryan 2008).

The third hypothesis was that a digital learning task characterized by both autonomy support and structure would have a positive effect on learning outcomes. This hypothesis was also confirmed. The positive interaction indicated that the combination of autonomy support and structure leads to better learning outcomes. Specifically, structure was associated with better learning outcomes in conditions that also provided autonomy support. A main effect of structure on learning outcomes was also found, but there was no main effect of autonomy support on learning outcomes. In other words, providing autonomy support had no impact on learning outcomes. It was only when it was combined with structure that autonomy support resulted in positive outcomes.

A possible explanation for this finding is that when students work on a digital learning task with autonomy support, but not structure, they may be too easily distracted from the purpose of the assignment. Students could be confused by the options offered when there is no corresponding guidance on the different steps they should take to reach a solution. Such confusion could lead students to lose sight of their objectives and become less focused on the goals of the task, which, in turn, could negatively affect their learning outcomes. These results suggest that structure facilitates metacognitive skills or self-regulated learning. Metacognitive skills comprise the control, monitoring, time-management, and self-regulation required by learning activities and problem-solving (Brown 1978).

In accordance with the research on metacognition, structure can be seen as a supportive tool that students use when they think through their planning and strategy to complete the task. Bannert (2004) shows that students with this type of metacognitive support tend to achieve better learning outcomes. Even adult users of web-based contexts indicate that they benefit from guided tools, such as a checklist, a help function, or an overview of phases and steps (Stoof et al. 2007.

In this study, we can see that perceived autonomy and perceived competence in digital learning are good predictors of intrinsic motivation. This finding is in accordance with the research on SDT, which shows that perceived autonomy and perceived competence increase intrinsic motivation (Deci and Ryan 2000, 2008). In contrast, learning outcomes appear to be affected only by perceived competence. Perceived autonomy by itself appears to have no additional effect on learning outcomes. The observation that perceived competence strongly predicted learning outcomes is in agreement with previous research that showed how classroom achievement is affected by students' beliefs about themselves and their academic competence (Deci et al. 1991; Pintrich and Schunk 2002). In addition, the direct effect of intrinsic motivation on learning outcome suggests that improved motivation enhances learning outcomes. The finding that student learning and education benefits from increased intrinsic motivation is in line with previous research based on the SDT (Ryan and Deci 2000a; Vansteenkiste et al. 2004). 
Limitations and future research

The present study, using an experimental design, shows significant evidence that the hypotheses were almost entirely confirmed. Nonetheless, several limitations of the study should be acknowledged.

The research consisted of a relatively short task that students completed in approximately an hour and a half. In future research, the effects of autonomy support and structure on student motivation and learning performance should be examined in digital tasks of varied duration that require students to spend more time completing them.

Because the student presentations could only be scored with eight points across four different criteria, there was limited variation in the learning outcome measure. Despite the limited variation, however, the effects of autonomy support and structure on learning performance were still significant.

Another limitation was that no pre- and post- measurements were administered. Instead, to overcome the fact that students were unlikely to have the same levels of prior knowledge and motivation, a large and representative sample was used. To control for possible interactions of the schools and the conditions on motivational and learning outcomes, students from all the appropriate classrooms within a school were randomly selected and assigned to one of the four experimental conditions. In follow-up work, pre- and postmeasurements should be included to control for the different levels of prior knowledge and motivation of students.

In addition, whereas the impact of autonomy support and structure was examined, the impact of specific aspects of autonomy support and structure (e.g. providing a rationale for a task that explains task relevance or using a roadmap) on motivation and learning performance has not been studied. Follow-up work should investigate the contributions of specific aspects of autonomy support and structure to clarify the mechanisms underlying the relationships found in this study. This is also the case for metacognitive skills and selfregulated learning. In particular, the results suggest that structure facilitates self-regulated learning. Students under the structured conditions were told the time limit for the task but those under the non-structured conditions were not. It is possible that the metacognitive skills used in this task related mainly to time management and that time management explained the effect to a greater extent than other metacognitive skills. Unfortunately, the investigation of this possibility fell beyond the scope of this study because it would have entailed the use of more than four experimental conditions. Thus, future research should take into account the effect of specific aspects of metacognitive skills under the structured condition to clarify the exact ways in which metacognitive skills have an effect on the motivation and learning performance of students.

The ultimate aim of the research was to examine the factors that increase the intrinsic motivation of students. Extrinsic motivation was excluded by giving students a task that was part of their regular curriculum and resulted in no associated score, grade, or reward upon completion. Despite these efforts, the existence of extrinsic motivation cannot be ruled out entirely. In follow-up research, a subscale should be included to measure extrinsic motivation to enable comparison of the levels of extrinsic motivation and intrinsic motivation that students experience.

It would also be interesting to investigate the ways in which the teacher can contribute to a more autonomy-supportive and structured digital learning environment. In a follow-up study, we intend to take into consideration the role of the teacher as a designer of digital learning tasks. 


\section{Conclusion}

In summary, the results of the present study show that when autonomy support and structure are present, digital learning tasks featuring PBL in a hypermedia environment lead to a positive effect on intrinsic motivation and learning outcomes of students. Because structure ensures that the digital learning task is consistent and clear, students are better able to make appropriate choices. Although providing structure has a positive effect on both intrinsic motivation and learning achievement, this effect was not observed for autonomy support. In the study, autonomy support without structure produced the least effective learning outcomes. The fact that structure matters in a digital learning task is not surprising. Because structure encourages metacognitive reflection and leads to more effective learning performance (Bannert 2004) it can be seen as a tool that students leverage in their learning process.

The combined impact of autonomy support and structure has not been previously studied in the context of digital learning. In this study, we found that both dimensions affected student motivation and learning outcomes, similarly to previous findings on learning in the classroom (Jang et al. 2010; Sierens et al. 2009). The findings of this study will not only help teachers to use digital learning tasks more effectively to improve the learning process but will also contribute to the discussion on SDT.

With regard to the implications of the present findings for educational practice, we believe that teachers will be able to use the results of this study to design better digital PBL tasks in a hypermedia environment. Digital learning tasks in the classroom often offer a lot of information but the lack of structure tends to increase the risk of information overload and cause students to lose sight of task objectives. This study suggests that the combination of autonomy support and structure contributes to the increased motivation and learning performance of students in the process of digital learning.

\section{References}

Azevedo, R., \& Witherspoon, A. M. (2009). Self-regulated learning with hypermedia. In D. J. Hacker, J. Dunlosky, \& A. C. Graesser (Eds.), Handbook of metacognition in education (pp. 319-339). New York: Routledge.

Bannert, M. (2004). Designing metacognitive support for hypermedia learning. In H. M. Niegemann, D. Leutner, \& R. Brünken (Eds.), Instructional design for multimedia learning (pp. 19-30). Münster: Waxmann.

Barrows, H. S. (1996). Problem-based learning in medicine and beyond: A brief overview. New Directions for Teaching \& Learning, 68(3), 3-12.

Baumeister, R. F., \& Leary, M. R. (1995). The need to belong: Desire for interpersonal attachments as a fundamental human motivation. Psychological Bulletin, 117, 497-529.

Black, A. E., \& Deci, E. L. (2000). The effects of instructors' autonomy support and students' autonomous motivation on learning organic chemistry: A self-determination theory perspective. Science Education, $84,740-756$.

Bowerman, B. L., \& O’Connell, R. T. (1990). Linear statistical models: An applied approach (2nd ed.). Belmont, CA: Duxbury.

Brown, A. L. (1978). Knowing when, where, and how to remember: A problem of metacognition. In R. Glaser (Ed.), Advances in instructional psychology (pp. 77-165). Hillsdale, NJ: Lawrence Erlbaum.

Clark, R. E., Yates, K., Early, S., \& Mouton, K. (2010). An analysis of the failure of electronic media and discovery-based learning. In K. H. Silber \& W. R. Foshay (Eds.), Handbook of improving performance in the workplace (pp. 263-297). San Francisco: Pfeiffer.

Connell, J. P. (1990). Context, self, and action: A motivational analysis of self-system processes across the life span. In D. Ciccetti \& M. Beeghly (Eds.), The self in transition: Infancy to childhood (pp. 61-97). Chicago: University of Chicago Press. 
Cordova, D., \& Lepper, M. (1996). Intrinsic motivation and the process of learning: Beneficial effects of contextualization, personalization, and choice. Journal of Educational Psychology, 88, 715-730.

DeCharms, R. (1968). Personal causation. New York: Academic Press.

Deci, E. L. (1975). Intrinsic motivation. New York: Plenum.

Deci, E. L., Eghrari, H., Patrick, B. C., \& Leone, D. R. (1994). Facilitating internalization: The selfdetermination theory perspective. Journal of Personality, 62, 119-142.

Deci, E. L., \& Ryan, R. M. (2000). The "what" and "why" of goal pursuits: Human needs and the selfdetermination of behaviour. Psychological Inquiry, 11, 227-268.

Deci, E. L., \& Ryan, R. M. (2008). Facilitating optimal motivation and psychological well-being across life's domains. Canadian Psychology, 49, 14-23.

Deci, E. L., Ryan, R. M., \& Williams, G. C. (1996). Need satisfaction and the self-regulation of learning. Learning and Individual Differences, 8, 165-183.

Deci, E. L., Vallerand, R. J., Pelletier, L. G., \& Ryan, R. M. (1991). Motivation and education: The selfdetermination perspective. Educational Psychologist, 26, 325-346.

Dunlap, J. C. (2005). Problem-based learning and self-efficacy: How a capstone course prepares students for a profession. Educational Technology Research and Development, 53, 65-85.

Flink, C., Boggiano, A. K., \& Barrett, M. (1990). Controlling teaching strategies: Undermining children's self-determination and performance. Journal of Personality and Social Psychology, 59, 916-924.

Grolnick, W. S., \& Ryan, R. M. (1987). Autonomy in children's learning: An experimental and individual difference investigation. Journal of Personality and Social Psychology, 52, 890-898.

Grolnick, W. S., \& Ryan, R. M. (1989). Parent styles associated with children's self-regulation and competence in schools. Journal of Educational Psychology, 81, 143-154.

Guay, F., Ratelle, C. F., \& Chanal, J. (2008). Optimal learning in optimal contexts: The role of selfdetermination in education. Canadian Psychology, 49, 233-240.

Hoffman, B., \& Richie, D. (1997). Using multimedia to overcome the problems with problem-based learning. Instructional Science, 25, 97-115.

Jang, H., Reeve, J., \& Deci, E. (2010). Engaging students in learning activities: It is not autonomy support or structure but autonomy support and structure. Journal of Educational Psychology, 102(3), 588-600.

Koestner, R., Ryan, R. M., Bernieri, F., \& Holt, K. (1984). Setting limits on children's behavior: The differential effects of controlling versus informational styles on intrinsic motivation and creativity. Journal of Personality, 52, 233-248.

Kuhl, J. (2000). A functional design approach to motivation and self-regulation: The dynamics of personality systems and interactions. In M. Boekaerts, P. Pintrich, \& M. Zeidner (Eds.), Handbook of selfregulation (pp. 111-163). San Diego, CA: Academic Press.

Lajoie, S. P. (1993). Computer environments as cognitive tools for enhancing learning. In S. P. Lajoie \& S. J. Derry (Eds.), Computers as cognitive tools (pp. 261-288). Hillsdale, NJ: Lawrence Erlbaum.

Lewalter, D., \& Krapp, A. (2004). The role of contextual conditions of vocational education for motivational orientations and emotional experiences. European Psychologist, 9, 210-221.

Liu, M., \& Bera, S. (2005). An analysis of cognitive tool use patterns in a hypermedia learning environment. Educational Technology Research and Development, 53, 5-21.

Liu, M., Horton, L., Olmanson, J., \& Toprac, P. (2011). A study of learning and motivation in a new media enriched environment for middle school science. Educational Technology Research and Development, 59, 249-265.

Martens, R., Gulikers, J., \& Bastiaens, T. (2004). The impact of intrinsic motivation on E-learning in authentic computer tasks. Journal of Computer Assisted Learning, 20, 368-376.

Mayer, R. E. (2011). Towards a science of motivated learning in technology-supported environments. Educational Technology Research and Development, 59, 301-308.

McAuley, E., Duncan, T., \& Tammen, V. V. (1987). Psychometric properties of the intrinsic motivation inventory in a competitive sport setting: A confirmatory factor analysis. Research Quarterly for Exercise and Sport, 60, 48-58.

Menard, S. (1995). Applied logistic regression analysis. Thousand Oaks, CA: Sage.

Morrison, G. R., \& Anglin, G. J. (2005). Research on cognitive load theory: Application to E-learning. Educational Technology Research and Development, 53, 94-104.

Narciss, S., \& Körndle, H. (1998). Problems and perspectives for the development of multimedia tools for teaching and learning in the Internet. European Psychologist, 3, 219-226.

Narciss, S., Proske, A., \& Körndle, H. (2007). Promoting self-regulated learning in web-based learning environments. Computers in Human Behavior, 23, 1126-1144.

Okan, Z. (2003). Edutainment: Is learning at risk? British Journal of Educational Technology, 34(3), 255-264. 
Patrick, H., Turner, J. C., Meyer, D. K., \& Midgley, C. (2003). How teachers establish psychological environments during the first days of school: Associations with avoidance in mathematics. Teachers College Record, 105, 1521-1558.

Pintrich, P., \& Schunk, D. H. (2002). Motivation in education: Theory, research, and applications (2nd ed.). Upper Saddle River, NJ: Prentice Hall.

Reeve, J., Deci, E. L., \& Ryan, R. M. (2004a). Self-determination theory: A dialectical framework for understanding socio-cultural influences on student motivation. In D. M. Mclnerney \& S. Van Etten (Eds.), Big theories revisited (pp. 31-60). Greenwich, CT: Information Age Publishing.

Reeve, J., \& Jang, H. (2006). What teachers say and do to support students' autonomy during a learning activity. Journal of Educational Psychology, 98, 209-218.

Reeve, J., Jang, H., Carrell, D., Jeon, S., \& Barch, J. (2004b). Enhancing students' engagement by increasing teachers' autonomy support. Motivation and Emotion, 28, 147-169.

Reeve, J., Nix, G., \& Hamm, D. (2003). Testing models on the experience of self-determination in intrinsic motivation and the conundrum of choice. Journal of Educational Psychology, 95, 375-392.

Reeve, J., Ryan, R. M., Deci, E. L., \& Jang, H. (2007). Understanding and promoting autonomous self-regulation: A self-determination theory perspective. In D. Schunk \& B. Zimmerman (Eds.), Motivation and selfregulated learning: Theory, research, and applications (pp. 223-244). New York: Lawrence Erlbaum.

Ryan, R. M. (1982). Control and information in the intrapersonal sphere: An extension of cognitive evaluation theory. Journal of Personality and Social Psychology, 43, 450-461.

Ryan, R. M. (1993). Agency and organization: Intrinsic motivation, autonomy and the self in psychological development. In J. Jacobs (Ed.), Nebraska symposium on motivation: Developmental perspectives on motivation (pp. 1-56). Lincoln, NE: University of Nebraska Press.

Ryan, R. M., \& Deci, E. L. (2000a). Self-determination theory and the facilitation of intrinsic motivation, social development, and well-being. American Psychologist, 55, 68-78.

Ryan, R. M., \& Deci, E. L. (2000b). Intrinsic and extrinsic motivations: Classic definitions and new directions. Contemporary Educational Psychology, 25, 54-67.

Ryan, R. M., \& Grolnick, W. S. (1986). Origins and pawns in the classroom: Self-report and projective assessments of individual differences in children's perceptions. Journal of Personality and Social Psychology, 50, 550-558.

Ryan, R. M., Kuhl, J., \& Deci, E. L. (1997). Nature and autonomy: Organizational view of social and neurobiological aspects of self-regulation in behavior and development. Development and Psychopathology, 9, 701-728.

Salomon, G., \& Almog, T. (1998). Educational psychology and technology: A matter of reciprocal relations. Teachers College Record, 100, 222-241.

Savery, J. R., \& Duffy, T. M. (1995). Problem-based learning: An instructional model and its constructivist framework. Educational Technology, 35, 31-38.

Sierens, E., Vansteenkiste, M., Goossens, L., Soenens, B., \& Dochy, F. (2009). The synergistic relationship of perceived autonomy support and structure in the prediction of self-regulated learning. British Journal of Educational Psychology, 79(1), 57-68.

Skinner, E. A., \& Belmont, M. J. (1993). Motivation in the classroom: Reciprocal effects of teacher behaviour and student engagement across the school year. Journal of Educational Psychology, 85, $571-581$.

Sobel, M. E. (1982). Asymptotic confidence intervals for indirect effects in structural equation models. Sociological Methodology, 13, 290-312.

Stipek, D. (1993). Motivation to learn: From theory to practice. Needham Heights, MA: Allyn \& Bacon.

Stoof, A., Martens, R., \& van Merriënboer, J. (2007). Web-based support for constructing competence maps: Design and formative evaluation. Educational Technology Research and Development, 55, 347-368.

Sweller, J. (2004). Instructional design consequences of an analogy between evolution by natural selection and human cognitive architecture. Instructional Science, 32, 9-31.

Toprac, P. (2011). Motivating by design: Using digital-game based learning techniques to create an interesting problem-based learning environment. In P. Felicia (Ed.), Handbook of research on improving learning and motivation through educational games: Multidisciplinary approaches (pp. 283-309). Hershey, PA: IGI Global.

Tucker, C. M., Zayco, R. A., Herman, K. C., Reinke, W. M., Trujillo, M., Carraway, K., et al. (2002). Teacher and child variables as predictors of academic engagement among low-income African American children. Psychology in the Schools, 39, 477-488.

Vansteenkiste, M., Simons, J., Lens, W., Sheldon, K. M., \& Deci, E. L. (2004). Motivating learning, performance, and persistence: The synergistic effects of intrinsic goal contents and autonomy supportive contexts. Journal of Personality and Social Psychology, 87, 246-260. 
White, R. W. (1959). Motivation reconsidered: The concept of competence. Psychological Review, 66, 297-333.

Zuckerman, M., Porac, J., Lathin, D., Smith, R., \& Deci, E. L. (1978). On the importance of self-determination for intrinsically motivated behavior. Personality and Social Psychology Bulletin, 4, 443-446.

Anne-Marieke van Loon is a Ph.D. Candidate in Educational Science at the Open University Heerlen, The Netherlands.

Anje Ros is a Lecturer at Fontys Hogescholen, Eindhoven, The Netherlands.

Rob Martens is Professor of Educational Science at the Open University, Heerlen, The Netherlands. 